\title{
META-ANALYSIS OF THE MAJOR CLINICAL FRACTURE RESULTS OF THE ZYGOMATIC-MAXILLARY COMPLEX WITH 1-POINT FIXATION: SUCCESS RATE AND COMPLICATIONS
}

\author{
Dr. Idiberto Jose Zotarelli Filho, MSc, Ph.D ${ }^{1}$ \\ ${ }^{1}$ Affiliation not available
}

September 17, 2020

\begin{abstract}
Introduction: Fractures of the zygomatic-maxillary complex (ZMC) are common facial fractures. Annually 5.8 million people die from trauma worldwide. According to WHO data, head and face injuries can account for half of traumatic deaths. Objective: To analyze the success rates of fracture stability of the ZMC, incidences of complications and aesthetic satisfaction after 1-point fixation. Methods: This study followed the rules of PRISMA, with publications from 2010 to 2020 . The ChiSquare Test and the Poisson's Probability Test were performed in relation to the occurrence of complications Low $=1$, Moderate $=2$ and $\mathrm{NO}=0$, adopting the $\alpha$-level less than 0.05 with a statistical difference for $95 \% \mathrm{CI}$. The R-sq $\left(\mathrm{R}^{2}\right)$ value was also analyzed among the complications variables. Results: The results of these studies showed in a general way that the use of 1-point fixation presented good results in the short, medium and long term, showing fracture stability, with or without open reduction. Complication rates were low and patients' satisfaction with aesthetics was considerable. Conclusion: The success rate of the 1-point fixation procedure for the zygomatic-maxillary complex is high, with minimal complications.
\end{abstract}

Keywords: Zygomatic-maxillary complex. 1-point fixation. Fracture stability. Complications. Aesthetics.

\section{Ramiro Murad Saad Neto, Idiberto José Zotarelli Filho ${ }^{2,3}$, Carlos Eduardo Xavier S. Ribeiro da Silva ${ }^{1}$}

1. Prevent Senior, Health plan, São Paulo/SP, Brazil

2. Faceres - Medical School of São José do Rio Preto/SP, Brazil.

3. Zotarelli-Filho Scientific Work, São José do Rio Preto/SP, Brazil.

\section{Introduction}

In the scenario of facial trauma, fractures of the Zygomatic-maxillary complex (ZMC) are common facial fractures. Annually 5.8 million people die from trauma worldwide [1]. Trauma mortality accounts for $10 \%$ of all causes of death. Thus, trauma is a worldwide public health problem. Still, trauma is the main cause of death among patients aged 1 to 44 years and the fourth major cause considering all age groups. According to WHO data, head and face injuries can represent half of traumatic deaths [1].

In this context, the ZMC is an important structure, serving as an important buttress of the middle third of the face. The ZMC also aesthetically projects anterolaterally to form the malar eminence and establish the width and medial-facial contour of the orbital border [2]. Attempts to treat ZMC fractures are to achieve stability and restore aesthetic appearance through three-dimensional reduction and rigid fixation. After adequate 
fracture reduction, it is important to maintain stability and rigid fixation to avoid functional impairment and aesthetic sequelae. Thus, open reduction and internal fixation have been used as a standard method for the treatment of these fractures [3].

Therefore, several surgical and technical procedures, including fixation of one, two and three points are used according to the severity and extent of ZMC fractures [4]. Among these techniques, some authors argue that fixation of just one point provides sufficient stability of the ZMC fracture when the ZMC fracture is not crushed $[5,6]$. At the moment, it is not yet clear which treatment, fixation of one point, fixation of two points or fixation of three points, is better [7]. In addition, there is a growing interest in minimally invasive procedures and concerns about scarring, further highlighting the use of fixing a point. Thus, fixing a point of the zygomatic- maxillary (ZM) buttress through a gingivobuccal incision has the advantage of not leaving an external scar $[8,9]$.

In this sense, the main indications for the use of fixation at 1 point of the tripod fracture are minimal or moderate displacement of the infra-orbital border in the zygoma tripod fracture, no ocular sign of diplopia or enophthalmia and comminuted infraorbital edge fractures in which internal fixation is difficult [10]. Successful repair requires not only an accurate diagnosis, but also a careful consideration of the complex three-dimensional anatomy, because even minimally displaced fractures in the ZMC can result in functional and aesthetic deformities [10].

Therefore, the present study aimed to analyze, through a meta-analysis, the success rates of fracture stability of the Zygomatic-maxillary complex, incidences of complications and aesthetic satisfaction after 1-point fixation.

\section{Methods}

\section{Study design}

This study followed the international model of Systematic Review and Meta-analysis, following the rules of PRISMA (preferred reporting items for systematic reviews and meta-analysis) [11]. Table 1shows the main variables of the present study that will be addressed according to the classification of the acronym PICOS $(\mathrm{P}=$ Patients; $\mathrm{I}=$ Intervention; $\mathrm{C}=$ Control; $\mathrm{O}=$ Outcomes; $\mathrm{S}=$ Study design $)$.

\section{Data sources and research strategy}

The search strategies for this systematic review was based on the descriptors (MeSH Terms) "Zygomaticmaxillary complex. 1-point fixation. Fracture stability. Complications. Aesthetics", with publications from 2010 to 2020, in order to analyze the most recent scientific publications. The research was carried out in June 2020 and developed at SCOPUS (Elsevier and non-Elsevier database), PUBMED (MEDLINE biomedical literature, life science magazines, and online books) and SCIENCE DIRECT (Elsevier database), including the National Institutes of Health RePORTER Grant database and clinical trial records. In addition, a combination of the keywords with the Booleans "OR", AND and the operator "NOT" was used to target scientific articles of interest. The title and abstracts was examined under all conditions. The research structure used in the databases is shown in Table 2.

\section{Selection of studies- Eligibility}

The inclusion criteria were clinical studies published from 2010 to 2020 on fractures of the ZMC and treatment with 1-point fixation, with or without open reduction, and with the use of bioabsorbable plates or not. Exclusion criteria were case report studies, review studies and meta-analysis or clinical studies that presented discreet results. 32 scientific articles were found at the clinical level. After applying the article selection filter, 15 articles were found, of which only 7 articles are strictly related to the analysis criteria of the present study to compose the meta-analysis (Figure 1).

\section{Risk of bias}

The quality of the evidence was classified as high, moderate, low or very low, according to the risk of bias in 
the body of evidence, openness of comparisons, accuracy and consistency in the effects of treatment. High quality of evidence has been attributed to well-designed randomized controlled trials (RCTs) with consistent results. The quality of the evidence was downgraded to moderate if 1 of the 4 criteria for the quality of the evidence had not been met and lower if 2 or more were not met. A low quality of evidence was attributed to non-randomized studies. The Cochrane instrument was be adopted to assess the quality of the included studies [12].

\section{Summary of Literary Findings}

The present study had some limitations as few clinical studies in the last ten years on 1-point fixation in the ZMC $(\mathrm{n}=7)$, with three studies being retrospective and three were prospective, and only one study was randomized.

\section{Statistical Analysis}

The statistical analysis of the data was performed by Dr. Idiberto José Zotarelli Filho and interpreted by the principal investigator. For data analysis, a database was built on the Microsoft Excel spreadsheet which was exported to the Minitab $18^{\circledR}$ statistical program (version 18, Minitab, LLC, State College, Pennsylvania, USA) (Minitabß) and also to the OriginPro@ 9 (DPR Group, Inc., Northampton, Massachusetts, USA). A common descriptive statistical analysis was performed, obtaining the values of total $n$, mean and standard deviation, confidence interval (CI), and percentage for all the variables. The Chi-Square and the Poisson Probability Test were performed in relation to the occurrence of complications Low $=1$, Moderate $=2$ and $\mathrm{NO}=0$, adopting the $\alpha$-level less than 0.05 with a statistical difference for $95 \% \mathrm{CI}$. The $\mathrm{R}$-sq $\left(\mathrm{R}^{2}\right)$ value was also analyzed among the complications variables, with the codes being adopted, low association $=<25 \%$, medium association $25 \%<\mathrm{X}<50 \%$ and high association $=>50 \%$.

\section{Results of Meta-analysis}

After the application of the descriptors (MeSH Terms) in the databases presented in the item Data sources and research strategy, 32 scientific articles were found at the clinical level. After applying the article selection filter for the last 10 years, 16 articles were found, of which only 7 articles are strictly related to the objective of the present study and entered the meta-analysis.

Table 3 presents the general data of each study analyzed, such as Type of study, number of patients in each study, the types of fixation points used, highlighting the priority for the analysis of 1-point fixation, the main results of each study and the Follow up or Period of analysis of each study. It also presents, in a manner described below, in Table 3, which were the main complications presented in some of the studies. Two of the studies used biodegradable plates to compare fracture stability with other plates.

Table 4 shows in quantitative terms the main complications in each study, using the numeric codes Low $=1$, Moderate $=2$ and $\mathrm{NO}=0$, as well as showing the success rates related to each study technique, highlighting that in one study the technique was used by three-dimensional photogrammetric analysis and in another study the ultrasound-guided technique was used and titanium and biodegradable plates were used.

After the statistical analysis to find out what the associations were between the complications of the studies by the Chi-Square Test, the results showed that there was no statistical difference between them, with $\mathrm{p}$ $=0.305>0.05$ and $\mathrm{R}^{2}=55.2 \%$ (high association). In addition, using the Poisson Probability Test, it was found that the probability of complications Low $=1$, Moderate $=2$ and $\mathrm{NO}=0$ was $0.65,0.28$ and 0.07 , respectively (Table 5). This same Table shows that the frequency of occurrence of NO-Complication was 5 (71.43\%), Low-Complication was 1 (14.29\%) and Moderate-Complication was 1 (14.29\%).

Figure 2 shows the graph with data on frequency, probability and percentage of occurrence of complications.

\section{Discussion}

The present study presented the state-of-the-art with presentation of a meta-analysis of the last ten years of publications of clinical studies on the use of 1-point fixation for fractures of the ZMC, both with the use of 
non-absorbable plates and bioabsorbable. The results of these studies showed in a general way that the use of 1-point fixation presented good results in the short, medium and long term, showing fracture stability, with or without open reduction. Complication rates were low and patients' satisfaction with aesthetics was considerable.

The studies of the present work also showed that the use of three-dimensional photogrammetric analysis and the ultrasound-guided technique can greatly favor the procedure and, in addition, they also showed that the use of biodegradable plates can offer good advantages, given that they showed equal stability of the fracture when compared with conventional plates. In this sense, achieving satisfactory results in the treatment of complex fractures of the middle and zygomatic maxillary face involves a series of decisions that include the approach of the zygomatic arch as the main point of treatment. In addition, a distinct pattern of fractures can generate more challenges to achieve satisfactory results.

The ZMC plays a fundamental role in the structure, function and aesthetic appearance of the facial skeleton. They can be responsible for approximately $40 \%$ of midface fractures. They are the second most common facial bone fracture after injuries to the nasal bones [3]. The fracture complex results from a direct impact on malar eminence and results in three distinct fracture components that interrupt the anchorage of the zygoma. In addition, the fracture components can result in temporal muscle shock, trismus (difficulty in chewing) and compromise the foramen / infraorbital nerve, resulting in hypesthesia in its sensory distribution [4].

In this context, a study performed a four-year retrospective review of all patients treated for ZMC fractures in the department of oral and maxillofacial surgery. A total of 245 patients were identified for fractures of the ZMC. Closed or open reduction methods were performed in order to treat the preservation of normal facial structure, sensory function, globe position and chewing functionality. Significant facial asymmetry that requires surgical revision occurs in $3-4 \%$ of patients. Postoperative infection rates have proved to be extremely low, and these infections almost always resolve with oral antibiotics. Thus, the long-term prognosis after repair of ZMC fractures is usually very good [5].

In this scenario, no clinical consensus was reached regarding the number of fixation points required when performing open reduction and internal fixation. A retrospective study of 211 patients over a 20 -year period looked at the usefulness of single-point fixation in the treatment of ZMC fractures. The average follow-up time was 3.4 months. Of the 211 patients, 162 with ZMC fractures were treated with single-point fixation. During the follow-up period, 1 patient suffered tooth loss because of a root present in the fracture line, 7 experienced intraoral exposure of the plaque, with 2 subsequently in exchange for the plaque and 8 developed wound infection. No patient required orthognathic surgery or cheek implant for malar asymmetry. No patient developed hypoglobus or enophthalmia, and none required a review of the internal fracture fixation [6]. Despite this, there is still controversy as to the ideal degree of exposure, reduction and anatomical fixation required during open reduction and internal fixation of fractures of the ZMC [7].

In addition, a prospective controlled study functionally assessed the behavior of the masticatory muscles (masseter and temporal) after fractures of the ZMC, evaluating the strength of the bite, the electromyography (EMG) and the mandibular movements. Group I consisted of 20 patients with unilateral fractures of the ZMC who were treated surgically with fixations of one, two or three points in the frontozygomatic, infraorbital or zygomatic maxillary buttress region. The control group in group II included 20 normal patients. Muscle activity was functionally assessed before and after surgery for a period of 6 months. The evaluation consisted of measuring the bite force, EMG analysis of the masseter and temporal muscles and measures of the mandibular movements. There was an increase in bite strength and electromyographic activity over the evaluated postoperative period, but at the end of 6 months, the values were still below the control levels for most patients. The maximum mouth opening increased considerably after surgery. According to the bite force and the EMG, the masticatory muscles returned to almost normal levels in the third month after surgery, mainly with 1-point fixation. Thus, this study supports the current clinical concept of minimized fixation in the treatment of ZMC fractures [8].

In addition, fracture of the zygomatic tripod is relatively common and usually requires open fixation with 
internal reduction through several incisions. However, the lateral incisions of the eyebrow sometimes leave unpleasant scars and, therefore, one point fixation can be used through a bucco-gingival incision to not leave scars in selected cases. Thus, a 5-year retrospective study with 30 patients compared the fixation of 1 point in the ZMC with the fixation of 2 points in the ZM and frontozygomatic (FZ) areas in tripod fractures. We investigated 14 patients with fixation of 1 point in the ZMC (group 1), 1 of whom had bilateral tripod fractures and 16 patients with fixation of 2 points in the ZM and FZ area (group 2). Of the 16 patients in group 2, $10(63 \%)$ complained of ugly scars at the site of the lateral incision of the eyebrow, while none of the patients in group 1 complained of external scars. None of the patients complained of bone movement and pain in the FZ area in both groups. In group 2, 4 of 16 patients (25\%) complained of palpability in the FZ area, while none in group 1 complained of palpability. The satisfaction score for the surgery was $9.4 \pm$ 1.6 in group 1 and $7.7 \pm 2.6$ in group $2(\mathrm{p}<0.05)$. In addition, two patients underwent surgery to remove plaque in group 2. None of the patients in group 1 complained of aesthetic problems, without fixation in the FZ area [9].

Zygoma is an important buttress of the medial-facial skeleton, which is often injured due to its prominent location. Zygoma fractures are classified according to Knight and North based on the direction of anatomical displacement and the pattern created by the fracture. In fractures of the ZMC, many incisions, such as the lateral eyebrow, upper lateral blepharoplasty, transconjunctival, subciliary, subciliary, subversal, intraoral and direct percutaneous approaches are useful [13].

Therefore, a study analyzed the cases of lateral incision of the forehead and fixation of 1 point and introduced the criteria for applying this selective approach. Among 70 patients with tripod fractures, 14 patients (20\%) underwent the 1-point fixation technique through lateral incisions of the forehead. The preoperative and postoperative displacements of the infra-orbital border were measured radiologically. Of these patients, 7 cases $(50 \%)$ were type III, 6 cases (43\%) type IV and 1 (7\%) type V, according to Knight. and North Classification. Simple fracture of the infra-orbital border was observed in 10 patients (71\%) and crushed fracture was observed in 4 patients (29\%). In 11 patients, the front zygomatic sutures were fixed with square microplates with 4 holes and $0.5 \mathrm{~mm}$ thick, and straight mini plates with 4 holes and $1.0 \mathrm{~mm}$ thick were used in 3 patients. Of the 14 tripod fractures, 6 (43\%) were associated with floor fractures. Seven had displacement of the infraorbital border (range 2.0-7.6 mm; mean, $4.6+/-0.8 \mathrm{~mm}$ ), and the other 7 had no displacement of the infraorbital border. After surgery, the deformities of the steps at the infraorbital edges were improved. All 14 patients were satisfied with the postoperative appearance [10].

Another 2019 retrospective study evaluated the results of stability and aesthetic appearance of fixing a point using a three-dimensional photogrammetric analysis. In nine months of medical record analysis, 34 patients with ZMC fractures were treated by fixing a point on the ZM buttress using non-sintered hydroxyapatite ( $\mathrm{u}-$ HA) / poly-L-lactide (PLLA) plates. The differences in the inter-malar height of the soft tissues between the fractured side and the non-fractured side were assessed by photogrammetric analysis with a three-dimensional camera (Morphius@) preoperatively and 1 week, 1 and 3 months after surgery. All patients achieved satisfactory bone stability and a symmetrical malar appearance. There was no statistically significant difference between 1 and 3 months after surgery. The comparison of differences in inter-malar bone height revealed a statistically significant difference between before and 6 months after surgery $(\mathrm{p}<0.01)$. Therefore, the use of three-dimensional photogrammetric analysis for fixation to a point of the ZM buttress using a u-HA / PLLA plate produced reliable, satisfactory and safe clinical results in patients with ZMC fractures [14].

In addition, a prospective study with 24 patients analyzed the precision and postoperative stability of the 1-point ultrasound-guided fixation in the ZM buttress for the treatment of ZMC fractures, without fracture separation in the frontal process of the zygomatic bone. The authors used titanium plates in the first 6 cases and biodegradable plates in the remaining 18 cases. The results suggested that the fixation of 1 point guided by ultrasound in the ZM buttress can provide an accurate reduction of the fractures of the ZMC without the separation of the frontal process of the fracture of the zygomatic bone. In addition, fracture stability has been established, even with the use of biodegradable plates [15].

Also, a randomized study with 20 patients performed to compare the fracture stability of the ZMC using 
biodegradable plates and titanium miniplates with fixation at one point. Patients with fractures of the ZMC were randomly selected and divided into two groups, which were divided into two subgroups. Group I patients were treated with a titanium miniplate in the zygomatic buttress and group II was treated with bioresorbable plates. The fixation of a point was carried out in the zygomatic buttress or in the frontozygomatic suture and it was observed that the site has been the most preferred site for rigid internal fixation in terms of stability, aesthetics and prevention of rotation of the fracture segment, vertical or horizontal axis. There was no significant difference in postoperative results between two groups, but the system still bioresorbable has some advantage over the titanium system, as these plates reabsorb for a period of time and do not interfere with growth and postoperative radiotherapy [16].

Still, the reduction and fixation of the zygomatic arch is a key point in the treatment of complex fractures of the middle face and zygomatic maxillary. High-impact frontal trauma can cause posterior displacement of the zygomatic bone, with a sagittal fracture of the root of the zygomatic arch extending posteriorly to the glenoid fossa. The fixation of the mini-plate and screw of this fracture requires a great detachment of soft tissues, being technically more difficult for an adequate fixation and increasing the risk of damage to the soft tissues. Therefore, a study described an operative approach for fixing this type of fracture using an adaptation of the delay screw technique. After the initial reduction of the zygomatic bone, the proximal segment of the zygomatic arch containing the sagittal fracture is anatomically reduced and a $2.0 \mathrm{~mm}$ titanium screw is placed with a lower inclination of $10^{\circ}$ to $15^{\circ}$ in the mastoid cells of the temporal bone, thus avoiding the placement of intracranial screws. Thus, excellent results in reduction and long-term stability were presented, it facilitates the surgical procedure, reduces the risk of damage to soft tissues and can reduce costs in comparison with the conventional mini-plate and fixation by screws [17].

\section{Conclusion}

The present study showed that the success rate of the 1-point fixation procedures for the Zygomatic-maxillary complex is high, with minimal complications.

\section{Limitations}

Despite the satisfactory results presented on the 1-point fixation technique of the Zygomatic-maxillary complex, the present study had some limitations as few studies on the 1-point fixation, limited number of studied patients and presented three retrospective studies, three prospective and only one randomized study.

\section{Declaration of conflicts of interest}

The authors declare nothing and all authors are aware of the article.

\section{References}

1. PAHO/WHO-Pan American Health Organization/World Health Organization. Available in: https://www.paho.org/bra/index.php?option=com_content\&view=article\&id=2989:traumas-matammais-que-as-tres-grandes-endemias-malaria-tuberculose-e-aids\&Itemid=839. Accessed in: May, 29-2020.

2. Sharma R, Muralidharan CG, Roy ID, Jain NK, Patrikar S. Radiological evaluation of sphenozygomatic suture fixation for restoration of orbital volume: A retrospective study. J Craniomaxillofac Surg. 2016 Dec;44(12):1903-1908. doi: 10.1016/j.jcms.2016.10.007. Epub 2016 Oct 20.

3. Abbas A, Syed IB, Abbas H, Abbas I. Paradigm in aetiology and management of zygomatic complex fractures in Pakistan. J Ayub Med Coll Abbottabad. 2012 Jul-Dec;24(3-4):193-6.

4. Olate S, Lima SM Jr, Sawazaki R, Moreira RW, de Moraes M. Surgical approaches and fixation patterns in zygomatic complex fractures. J Craniofac Surg. 2010 Jul;21(4):1213-7. doi: 10.1097/SCS.0b013e3181e1b2b7.

5. Balakrishnan K, Ebenezer V, Dakir A, Kumar S, Prakash D. Management of tripod fractures (zygomaticomaxillary complex) 1 point and 2 point fixations: A 5-year review. J Pharm Bioallied Sci . 2015;7(Suppl 1):S242-S247. doi:10.4103/0975-7406.155937. 
6. Shokri T, Sokoya M, Cohn JE, Bahrami A, Inman J, Ducic Y. Single-Point Fixation for Noncomminuted Zygomaticomaxillary Complex Fractures-A 20-Year Experience. J Oral Maxillofac Surg. 2020 May;78(5):778-781. doi: 10.1016/j.joms.2019.12.030.

7. Jazayeri HE, Khavanin N, Yu JW, Lopez J, Shamliyan T, Peacock ZS, Dorafshar AH. Fixation Points in the Treatment of Traumatic Zygomaticomaxillary Complex Fractures: A Systematic Review and MetaAnalysis. J Oral Maxillofac Surg. 2019 Oct;77(10):2064-2073. doi: 10.1016/j.joms.2019.04.025.

8. Panchanathan S, Saranathan M, Kamalakaran AK, Duraisamy K. Functional Evaluation of the Behavior of Masticatory Muscles in Zygomaticomaxillary Complex Fracture: A Prospective Study. J Contemp Dent Pract. 2016 Jun 1;17(6):463-9.

9. Kim ST, Go DH, Jung JH, Cha HE, Woo JH, Kang IG. Comparison of 1-point fixation with 2-point fixation in treating tripod fractures of the zygoma. J Oral Maxillofac Surg. 2011 Nov;69(11):2848-52. doi: 10.1016/j.joms.2011.02.073. Epub 2011 Jun 12.

10. Hwang K. One-point fixation of tripod fractures of zygoma through a lateral brow incision. J Craniofac Surg. 2010 Jul;21(4):1042-4. doi: 10.1097/SCS.0b013e3181e48607.

11. Moher D, Liberati A, Tetzlaff J, Altman DG, The PRISMA Group (2009) Preferred Reporting Items for Systematic Reviews and Meta-Analyses: The PRISMA Statement. PLoS Med 6(7): e1000097. https://doi.org/10.1371/journal.pmed.1000097.

12. Higgins J, Green S. Cochrane Handbook for Systematic Reviews of Interventions. Version 5.1.0 [updated March 2011]. The Cochrane Collaboration; 2011.

13. Ji SY, Kim SS, Kim MH, Yang WS. Surgical Methods of Zygomaticomaxillary Complex Fracture. Arch Craniofac Surg. 2016 Dec;17(4):206-210. doi: 10.7181/acfs.2016.17.4.206. Epub 2016 Dec 23.

14. Kim SY, Nam SM, Park ES, Kim YB. Evaluation of one-point fixation for zygomaticomaxillary complex fractures using a three-dimensional photogrammetric analysis. J Otolaryngol Head Neck Surg. 2019 Jul 30;48(1):36. doi: 10.1186/s40463-019-0359-2.

15. Sato A, Imai Y, Muraki K, Tachi M. Reliability of Ultrasound-Guided One-Point Fixation for Zygomaticomaxillary Complex Fractures. J Craniofac Surg. 2019 Jan;30(1):218-222. doi: 10.1097/SCS.0000000000005133.

16. Tripathi N, Goyal M, Mishra B, Dhasmana S. Zygomatic complex fracture: A comparative evaluation of stability using titanium and bio-resorbable plates as one point fixation. Natl J Maxillofac Surg. 2013 Jul;4(2):181-7. doi: 10.4103/0975-5950.127648.

17. Ribeiro Ribeiro AL, Rodrigues TM, Alves-Junior Sde M, Pinheiro Jde J. Interfragmentary screw fixation of the zygomatic arch in complex midface and zygomaticomaxillary fractures. J Oral Maxillofac Surg. 2015 Mar;73(3):494-8. doi: 10.1016/j.joms.2014.09.028. Epub 2014 Oct 17.

Table 1. PICOS (PATIENT, PROBLEM, POPULATION; INTERVENTION; COMPARISON, CONTROL; OUTCOMES; STUDY DESIGN) FRAMEWORK.

\begin{tabular}{ll}
\hline Population & Adults with zygomaticomaxillary complex fractures (quadripod fracture, quadramalar fracture, tripod \\
Intervention & 1-point fixation with or without miniplates and reduction. \\
CONTROL & Different types of plates; Use of three-dimensional photogrammetric analysis; Use of ultrasound-guided \\
outcomes & Patient satisfaction with function and aesthetics results; Stable fracture fixation; Pain; Quality of life; \\
STUDY DESIGN &
\end{tabular}

Table 2. Example of the research structure in PubMed, the same search strategy was used in the other databases.

\begin{tabular}{ll}
\hline PubMed & Zygomatic-maxillary complex OR Fracture OR \\
1-point fixation \\
\hline \multirow{2}{*}{ PubMed } & AND \\
& Fracture stability OR Complications OR \\
& Aesthetic OR Masticatory force Aest
\end{tabular}




\section{NOT}

PubMed

Case report OR 2 to 4 point fixings

Figure 1. Flow chart.

Table 3. General data of the selected studies to compose the meta-analysis.

* 7 experienced intraoral plaque exposure, with 2 subsequently in exchange for plaque complications, 8 infections.

\begin{tabular}{|c|c|c|c|c|c|}
\hline $\begin{array}{l}\text { Authors }(\mathrm{n}=7) \\
\text { /Major points } \\
\text { and results }\end{array}$ & Type of Study & $\mathrm{N}$ patients & $\begin{array}{l}\text { Procedures ( } \\
\text { Fixings-Points } \\
\text { ) }\end{array}$ & Major Results & $\begin{array}{l}\text { Follow up or } \\
\text { Analysis } \\
\text { period }\end{array}$ \\
\hline $\begin{array}{l}\text { Shokri et al., } \\
2020\end{array}$ & Prospective & 162 & 1 & $\begin{array}{l}\text { The ZMC } \\
\text { fracture } \\
\text { responded well } \\
\text { with the } \\
\text { 1-point } \\
\text { fixation. }\end{array}$ & 3.4 months \\
\hline $\begin{array}{l}\text { Panchanathan } \\
\text { et al., } 2016\end{array}$ & $\begin{array}{l}\text { Controlled } \\
\text { prospective }\end{array}$ & $\begin{array}{l}40(\mathrm{n}=20 \\
\text { control })\end{array}$ & $\begin{array}{l}1(\mathrm{n}=4) 2 \\
(\mathrm{n}=12) 3(\mathrm{n}=4)\end{array}$ & $\begin{array}{l}\text { Increased bite } \\
\text { strength and } \\
\text { muscle activity. }\end{array}$ & 6 months \\
\hline $\begin{array}{l}\text { Kim et al., } \\
2011\end{array}$ & Retrospective & 30 & $\begin{array}{l}1(\mathrm{n}=14) 2 \\
(\mathrm{n}=16)\end{array}$ & $\begin{array}{l}\text { There was no } \\
\text { statistical } \\
\text { difference } \\
\text { between the } \\
\text { three types of } \\
\text { fixation. }\end{array}$ & $\begin{array}{l}\text { Evaluation of } \\
5 \text {-year medical } \\
\text { records }\end{array}$ \\
\hline Hwang, 2010 & Retrospective & 14 & 1 & $\begin{array}{l}\text { Fixing a point } \\
\text { on the ZMC } \\
\text { can prevent } \\
\text { unpleasant } \\
\text { scarring and } \\
\text { provide high } \\
\text { satisfaction in } \\
\text { patients with } \\
\text { tripod } \\
\text { fractures. }\end{array}$ & $\begin{array}{l}\text { Evaluation of } \\
1.5 \text {-year } \\
\text { medical } \\
\text { records }\end{array}$ \\
\hline $\begin{array}{l}\text { Kim et al., } \\
2019\end{array}$ & Retrospective & 34 & $1^{*}$ & $\begin{array}{l}\text { The } \\
\text { deformities of } \\
\text { the steps of } \\
\text { the } \\
\text { infraorbital } \\
\text { edges were } \\
\text { improved. }\end{array}$ & $\begin{array}{l}\text { Evaluation of } \\
\text { medical } \\
\text { records of } 9 \\
\text { months }\end{array}$ \\
\hline
\end{tabular}




\begin{tabular}{|c|c|c|c|c|c|}
\hline $\begin{array}{l}\text { Authors }(n=7) \\
\text { /Major points } \\
\text { and results }\end{array}$ & Type of Study & $\mathrm{N}$ patients & $\begin{array}{l}\text { Procedures ( } \\
\text { Fixings-Points } \\
\text { ) }\end{array}$ & Major Results & $\begin{array}{l}\text { Follow up or } \\
\text { Analysis } \\
\text { period }\end{array}$ \\
\hline $\begin{array}{l}\text { Sato et al., } \\
2019\end{array}$ & Prospective & 24 & $1^{* *}$ & $\begin{array}{l}\text { All patients } \\
\text { were satisfied } \\
\text { with the } \\
\text { postoperative } \\
\text { appearance. }\end{array}$ & 6 months \\
\hline $\begin{array}{l}\text { Tripathi et } \\
\text { al., } 2013\end{array}$ & Randomized & 20 & $1^{* * *}$ & $\begin{array}{l}\text { All patients } \\
\text { achieved } \\
\text { satisfactory } \\
\text { bone stability } \\
\text { and a } \\
\text { symmetrical } \\
\text { malar } \\
\text { appearance. }\end{array}$ & 6 months \\
\hline
\end{tabular}

** Group I: Titanium. Swelling was observed in all patients on the first postoperative day. Diplopia was observed in $5 \%$ of patients for 3 months in subgroup A. Palpability was also observed in $5 \%$ of cases in subgroup B for 6 months. On the contrary, enophthalmia, paraesthesia, screw breakage, plaque exposure, infection at the site, malocclusion and thermal sensitivity were not observed in the postoperative period and the bite efficiency of all patients was normal in the postoperative period.

** Group II: Biomaterial. As the postoperative complication found in group II - Swelling was observed in all patients on the first postoperative day. Diplopia was observed in $10 \%$ of patients, screw rupture was observed in $10 \%$ of the patient at the time of surgery, plaque exposure and infection at the site was observed in $10 \%$ of cases in the 6 -month review. On the contrary, enophthalmia, paresthesia, palpability, thermal sensitivity and malocclusion were not observed in any patient in the postoperative period. Bite efficiency was considered normal in all patients.

$* * * \mathrm{n}=10$ with titanium plates and $\mathrm{n}=10$ with biodegradable plates.

Table 4. Data on the findings of complications and success rate of the studies addressed.

\begin{tabular}{lll}
\hline Authors & Complications (Low=1, Moderate=2 and NO=0) & Technique Success Rate $(\%)$ \\
\hline Shokri et al., 2020 & 2 & 90.0 \\
Panchanathan et al., 2016 & 0 & 74.2 \\
Kim et al., 2011 & 0 & 100 \\
Hwang, 2010 & 0 & 100 \\
Kim et al., 2019* & 0 & 100 \\
Sato et al., 2019 & 0 & 100 \\
Tripathi et al., 2013** & 1 & 70 \\
\hline
\end{tabular}

* Used non-sintered hydroxyapatite (u-HA) / poly-L-lactide (PLLA) plates and three-dimensional photogrammetric analysis

** Guided by ultrasound and used titanium and biodegradable plates.

Table 5. Statistical results of the Chi-Square analysis, Poisson's Probability, frequency and percentage of occurrence of the levels of complications, with $\mathrm{p}<0.05$ with statistical difference, CI95\%. 
Complications

(Low $=1$,

Moderate $=2$ and Poisson

$\mathrm{NO}=0)$ Probability

\section{Frequency}

0.65

0.28

0.07

2 CHI-SQUARE

TEST p-

value $=0.305>0.05$

$\mathrm{R}^{2}=55.2 \%$

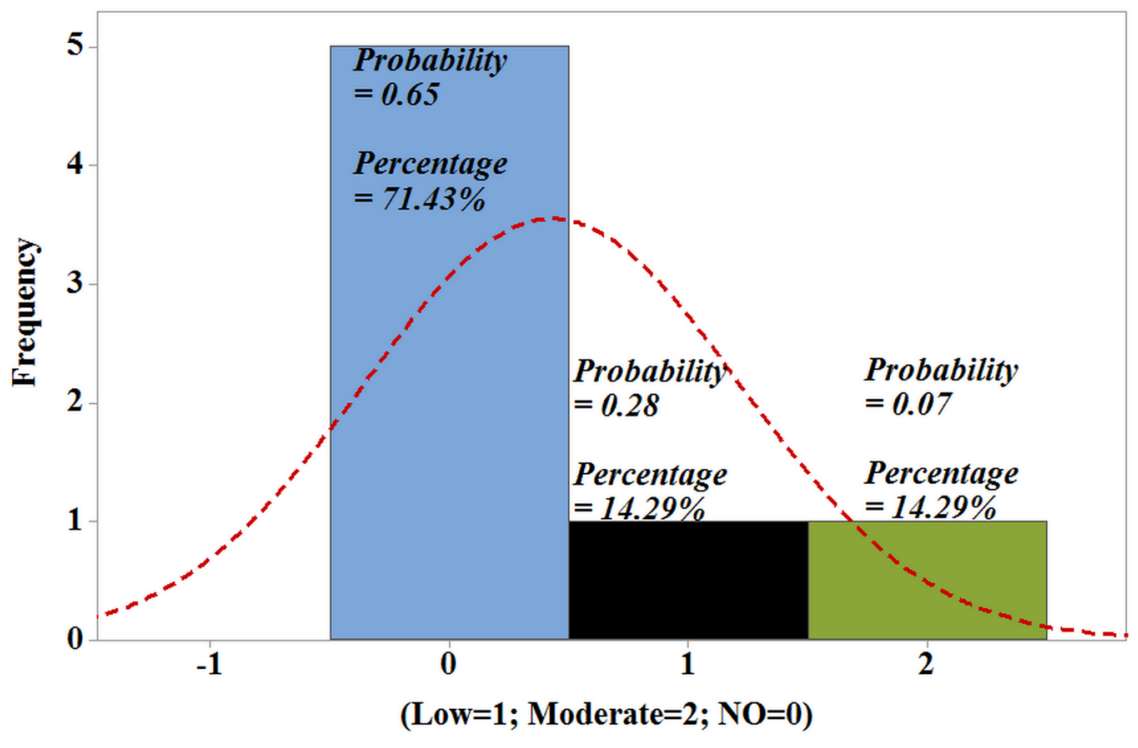

Figure 2. Graph showing the comparisons between the levels of complications, being Low $=1$, Moderate $=2$ and $\mathrm{NO}=0$. 